\title{
Claims Data Analysis of Tumor Necrosis Factor Inhibitor Treatment Dosing Among Patients with Rheumatoid Arthritis: A Systematic Review of Methods
}

\author{
Gundula Krack $^{1,2} \cdot$ Henning Zeidler ${ }^{3} \cdot$ Jan Zeidler $^{4}$
}

Published online: 23 August 2016

(c) The Author(s) 2016. This article is published with open access at Springerlink.com

\begin{abstract}
Background With tumor necrosis factor inhibitors, changes of dosing, switching between drugs, insufficient adherence, and persistence are frequent in rheumatoid arthritis. Because this is often associated with decreased efficiency and increased costs, dosage analyses based on claims data are of increasing interest for healthcare providers and payers. Nevertheless, no standardized methods exist to ensure high-quality research.

Objective In this review, we compare and discuss applied methods in claims data-based dosage analyses of tumor necrosis factor inhibitor prescriptions in patients with rheumatoid arthritis.

Methods A systematic review was performed in accordance with the Preferred Reporting Items for Systematic Reviews and Meta-Analyses statement. The dosage
\end{abstract}

analysis methods performed within the selected studies were classified into switching, persistence, adherence, and dosage-change analyses, and were then compared and finally discussed.

Results A total of 45 studies were found to be relevant. In most studies, a change in dose or persistence was evaluated, followed by switching and adherence analyses. Analyses of changed dose exhibit the most extensive variation of methods. We divided them into three principal methods, where a specified reference dose is compared with (1) the last dose, (2) any dose, or (3) all doses. Conclusion The systematic review identified a high variation of methods. Our results may be helpful for choosing appropriate methods in future studies. The results also demonstrate the need for evidence-based recommendations of methods used in claims data research.

Gundula Krack

krack@bwl.lmu.de

1 Munich Center of Health Sciences (MC-Health), Ludwig Maximilian University of Munich, Ludwigstraße 28, 80539 Munich, Germany

2 German Research Center for Environmental Health (GmbH), Institute of Health Economics and Health Care Management, Helmholtz Zentrum München, Neuherberg, Germany

3 Division of Immunology and Rheumatology, Medical School Hannover, Hannover, Germany

4 Center for Health Economics Research Hannover (CHERH), Leibniz University Hannover, Hannover, Germany 


\section{Key Points}

Dosage analyses of switching differ with respect to the implementation of a time frame and with respect to controlling the discontinuation of the previous therapy.

Dosage analyses of persistence are characterized by the criteria used for therapy discontinuation. These are allowance of switching to other treatments and the therapy discontinuing prescription gap.

Proportion of days covered and the medication possession ratio with fixed or variable follow-ups are the most frequently used methods for claims data analyses of adherence.

Dosage change analyses exhibit the most extensive variation of methods. They differ with respect to the type of dose comparison and with respect to other restrictions that are necessary to define a dose escalation or a decrease in dose. These restrictions refer for example to the length of prescription intervals and to the difference between a changed dose and its reference.

We divide changes in dose into three principal methods: a comparison of (1) the last dose, (2) any dose, or (3) all doses to a specified reference dose. Reference doses are the index, maintenance, recommended, and previous dose.

\section{Introduction}

Tumor necrosis factor (TNF) inhibitors are substantial components in the management of patients with rheumatoid arthritis (RA). RA is a systemic, inflammatory, chronic autoimmune disease of the peripheral joints. It leads to joint swelling and pain with decreasing mobility. The messenger substance TNF- $\alpha$ triggers the inflammatory process of RA. Because TNF-inhibitors are able to block TNF- $\alpha$ itself or the receptors of the target cells, they can influence the inflammatory process directly, reduce the progression of the disease, and improve symptoms [1]. Inadequate compliance or adherence to therapy could complicate the therapeutic success and cause higher therapy costs [2]. TNF inhibitors are costly and changes in prescription may significantly impact healthcare costs $[3,4]$. Therefore, investigating changes in therapy is important to patients, healthcare providers, and healthcare payers. Because claims data analyses allow for insight into drug prescriptions under real-life conditions, they are powerful instruments for evaluating healthcare provision [5].

High-quality research is needed to provide good evidence on comparative drug dosing analyses in real life, but there are no standardized methods available. No systematic review has been conducted that classifies and compares methods used in studies reporting dosage analyses of TNF inhibitor prescriptions in patients with RA on the basis of claims data. Therefore, the objective of the present study is to provide such a review, comparing the methods used in switching, persistence, adherence, and dosage-change analyses. Finally, the resulting findings may provide guidance for the most appropriate application of the methods in future research and contribute to evidence-based recommendations for dosage analyses with claims data.

This review is structured as follows: first, we present the methodology of our review, comprising the eligibility criteria, the search strategy, and the handling of outcomes and data. Second, we present an overview of the identified studies and their characteristics, followed by classification of their methods. We end with a discussion of the identified methods.

\section{Methods}

To identify the relevant literature, a systematic review following the guidelines of the Preferred Reporting Items for Systematic Reviews and Meta-Analyses statement was conducted on February 12, 2016. First, the selection criteria were defined. Second, a systematic search, based on these selection criteria, in the MEDLINE, BIOSIS Previews, EMBASE Alert, EMBASE, German Medical ScienceJournals and Meetings and SciSearch databases, provided by the German Institute for Medical Documentation and Information [6] platform, was performed. Search terms used corresponded to the indications (RA), the intervention (TNF inhibitors), claims data, and dosage analyses, as well as their results, such as changes in dose, switching, adherence, and discontinuation. Synonyms for each term in either the German or the English language were used. Subsearches for each search term were applied and finally combined. The full search code can be provided on request. From the identified literature, the relevant studies were selected based on the following inclusion criteria:

1. Studies must be full publications written in either the German or the English language.

2. The study population must include at least one subgroup of RA patients.

3. The analyses must be based on claims data.

4. The course of drug therapy, such as switching drugs, changes in dosage, adherence, or persistence, must be investigated. 
5. The therapy must involve at least one TNF inhibitor.

6. The dosage analyses must be an essential part of the study, meaning outcomes of the dosage analyses must be reported.

The comparison of methods is basically a comparison of different claims data-based definitions of the various outcomes. To this end, the identified studies were classified into their outcomes of the switching, adherence, persistence, and dosage-change analyses.

Switching analysis was classified based on the time frame and information on whether discontinuation of the former drug was ensured. The time frame is the gap between the last prescription of the former drug and the new one that is allowed at maximum, before a therapy is considered to be terminated.

We use the terms persistence and adherence in accordance with the International Society of Pharmacoeconomics and Outcome Research because the terms adherence and persistence are not used consistently in the identified literature [7]. According to the International Society of Pharmacoeconomics and Outcome Research, persistence describes the duration of continuous treatment. Methods of persistence analyses are classified by the maximum time frame allowed and information on whether a switch between drugs within a drug class was accepted. The time frame is the maximum prescription gap that was still allowed between two prescriptions to assume persistency. Otherwise the therapy was considered to be terminated.

In contrast to persistence, adherence is a measure of the extent to which a patient adheres to his/her treatment as recommended or prescribed. It is typically bound to a value between 1 and 0 , where 1 indicates perfect adherence, and 0 indicates no adherence. We classified adherence analyses based on the measure of adherence that was used in the identified literature.

A changed dose is deemed as either an increase or decrease in prescription dose. For dosage change analyses, we defined three principal methods based on the type of doses that were compared. These are (1) the last dose vs. reference, (2) any dose vs. reference, and (3) all doses vs. reference. In studies being selected to category (1), any change or a certain minimum change of the last prescription dose within the follow-up, compared with a reference dose was defined as a dose escalation or dose reduction. In category (2), all doses within the study period were compared with a reference. If any change in dose, as defined in the corresponding study, can be observed, the associated patient was flagged as having had a dose escalation or dose reduction. In category (3), mean doses of all prescriptions within a certain period were calculated and compared with a reference. The periods chosen varied.
A quantitative assessment of quality, in terms of validity and sensitivity, exceeds the scope of this review and should be subjected to further research.

\section{Results}

\subsection{Search Results}

The process of selecting references included in this review is shown in Fig. 1. After excluding duplicates and articles not complying with the inclusion criteria, 45 studies were included in the present review. An overview of the selected publications is given in Table 1. In most studies, treatment with adalimumab (ADA), etanercept (ETN), and/or infliximab (IFX) was evaluated. Because golimumab (GLM) and certolizumab pegol (CP) have only been available since 2009 , there are only a few dosage analyses available in recent studies. No study analyzing dosing of biosimilars was found. In most studies, the change in dose $(n=27)$ or persistence $(n=26)$ was evaluated, followed by switching analyses $(n=20)$. Adherence was only investigated in 14 studies. The claims data of the studies identified were mostly generated from different US databases. Only four of them used Korean, Swiss, German, or Italian claims data [4, 8-10].

\subsection{Definitions of Switching, Persistence, and Adherence}

\subsubsection{Switching}

Switching of therapy influences persistence because it often terminates the current treatment. Available studies explored either switching or they attempted to analyze characteristics of subgroups of people who switched drugs [11]. A switch is defined as a change between certain medications. Some studies defined a maximum time frame of various lengths between the last prescriptions of the former drug and the prescription of the new drug. The switch needs to take place within that frame, otherwise the therapy is considered to be terminated. Some studies also indicated if they had ensured the discontinuation of the former drug to avoid confusing co-medication with switching. The various definitions applied are shown in Table 2.

The termination of the previous therapy was assured in five studies [8, 9, 12-14]. Most studies did not make any statement regarding termination of previous therapy. A maximum time frame was rarely specified. The length of this period mostly depends on the days of supply (DOS) ${ }^{1}$ of

\footnotetext{
${ }^{1}$ DOS are either given in the claims data or they refer to the expected prescription interval.
} 
Fig. 1 Process of selection

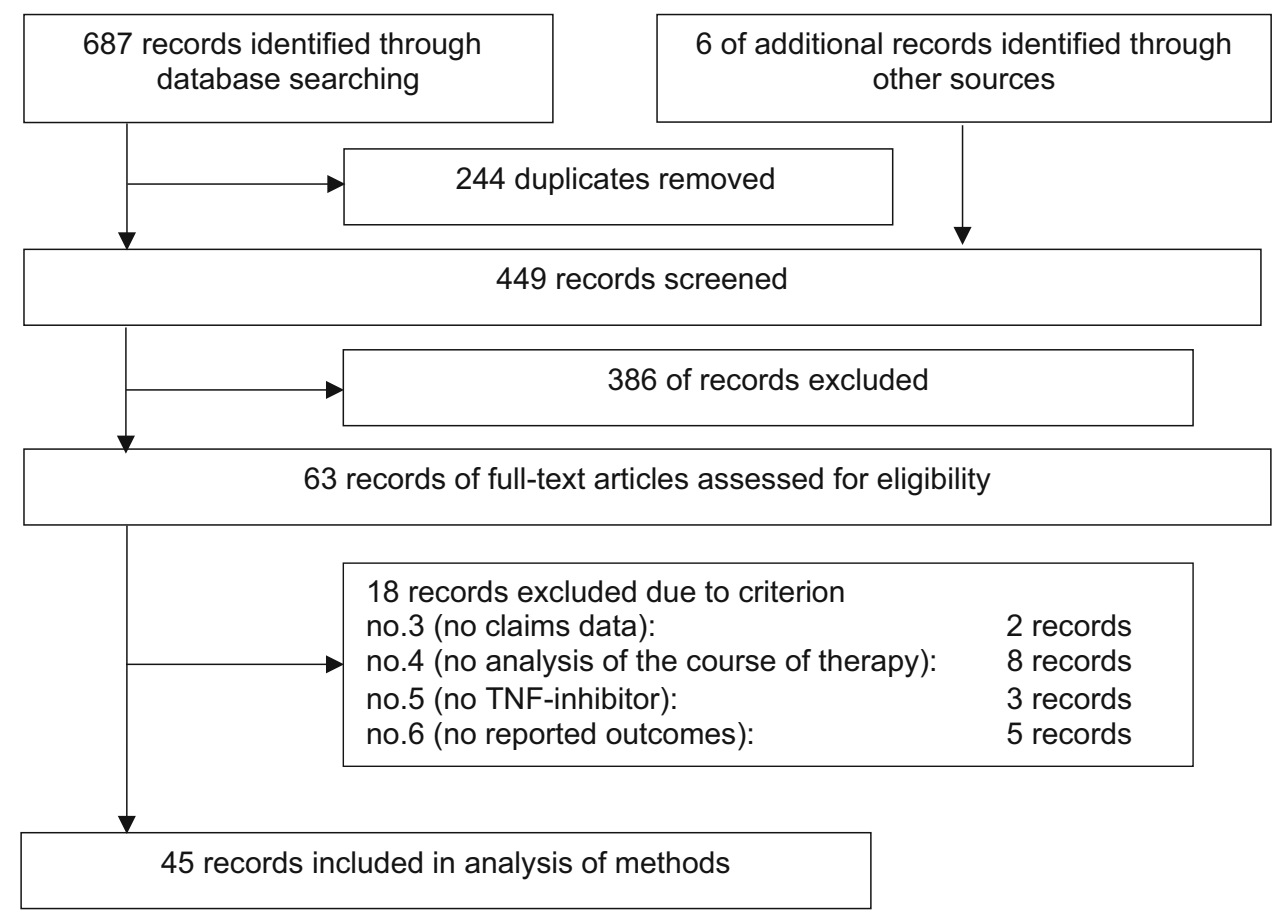

the last prescription of the former medication plus an additional period of 30 or 90 days $[9,13,15]$. In one case, a time frame of $200 \%$ of the prescribed index-DOS was chosen instead [16]. In contrast, in four cases, a time frame was not required [17-20]. It should be noted that most studies did not indicate whether or not a time frame was implemented.

\subsubsection{Persistence}

A therapy is terminated either if a switch to another medication occurs or the time frame, meaning the gap between two prescriptions, gets too large. Table 3 lists the allowable switches between medications and which time frames were accepted for the assumption of persistency. With the exception of Curkendall et al., who evaluated persistence for several drugs simultaneously, no other authors explicitly allowed a switch in medication [21]. The accepted gap between two prescriptions mostly depends on DOS or the expected dosing intervals plus a further period of 30-90 days. Expectations are usually drawn from the therapy recommendations. In contrast, a fixed maximum period was defined in six studies [8, 19, 20, 22-24].

\subsubsection{Adherence}

Adherence is sometimes difficult to evaluate in claims datasets because most TNF inhibitors are injected by the patients themselves, and thus detailed information is missing in the database. This is not the case with IFX, which is by intravenous (i.v.) application in a clinical setting. Therefore, this is registered in the claims data. In either case, it can be observed whether the prescriptions are refilled within DOS-supplied or within recommended intervals. Thus, the fraction of days with medication on hand can be determined, which is fundamental for the calculation of measures of adherence.

For the most part, adherence was examined with ratios such as the medication possession ratio (MPR) [2, 12, 21, 22, 25-28], the proportion of days covered (PDC) $[13,22,23,28,29]$, or the compliance ratios of Harley et al. or Tkacz et al. [30, 31]. In contrast to the MPR, which equals the sum of DOS divided by the treatment period, the PDC considers the days with DOS available to the patient by taking the storability of drugs into account.

The MPR was calculated for fixed [2, 25] or variable follow-ups [12, 21, 22] with

$\mathrm{MPR}=\frac{\sum_{t=0}^{T_{\mathrm{f}}} \mathrm{DOS}}{T_{\mathrm{f}}}$,

where $T_{\mathrm{f}}$ indicates the follow-up. Variable follow-ups depend on individual treatment periods. The treatment usually starts with the index date, the date of the first prescription and ends with the end of study period or with the termination of the treatment, whereas fixed follow-ups are the same for all patients. In that case, the length of the follow-up is specified ex ante. Only patients who are persistent within that period are analyzed. With fixed 
Table 1 Overview of selected publications according to the prescribed TNF inhibitors and the mode of change in dosing

\begin{tabular}{|c|c|c|c|c|c|c|c|c|c|c|c|}
\hline \multirow[t]{2}{*}{ Author [ref.], year } & \multicolumn{5}{|c|}{ TNF inhibitors } & \multicolumn{4}{|c|}{$\begin{array}{l}\text { Mode of change in } \\
\text { dosing: switching (S), } \\
\text { persistence }(\mathrm{P}) \text {, } \\
\text { adherence }(\mathrm{A}) \text {, change } \\
\text { (C) }\end{array}$} & \multicolumn{2}{|l|}{ Source of claims data } \\
\hline & IFX & $\mathrm{ADA}$ & ETN & GLM & $\mathrm{CP}$ & $\mathrm{S}$ & $\mathrm{P}$ & A & $\mathrm{C}$ & Provider & Country \\
\hline Harley et al. [30], 2003 & $\mathrm{x}$ & & $\mathrm{x}$ & & & & & $\mathrm{x}$ & $\mathrm{x}$ & A large health plan & USA \\
\hline Gilbert et al. [38], 2004 & $\mathrm{x}$ & & $\mathrm{x}$ & & & & & & $\mathrm{x}$ & IMS PharMetrics & USA \\
\hline Berger et al. [32], 2005 & $\mathrm{x}$ & & & & & & & & $\mathrm{x}$ & Constella & USA \\
\hline Etemad et al. [42], 2005 & $\mathrm{x}$ & & $\mathrm{x}$ & & & & & & $\mathrm{x}$ & A large health plan & USA \\
\hline Ollendorf et al. [46], 2005 & $\mathrm{x}$ & & & & & & & & $\mathrm{x}$ & IMS PharMetrics & USA \\
\hline Weycer et al. [11], 2005 & $\mathrm{x}$ & & $\mathrm{x}$ & & & & & & $\mathrm{x}$ & $\begin{array}{l}\text { Constella } \\
\text { Ingenix LabRx }\end{array}$ & USA \\
\hline Grijalva et al. [12], 2007 & $\mathrm{x}$ & $\mathrm{x}$ & $\mathrm{x}$ & & & $\mathrm{x}$ & $\mathrm{x}$ & $\mathrm{x}$ & & Tenessee Medicaid & USA \\
\hline Curkendall et al. [21], 2008 & & $\mathrm{x}$ & $\mathrm{x}$ & & & & $\mathrm{x}$ & $\mathrm{x}$ & & MarketScan & USA \\
\hline Tang et al. [47], 2008 & $\mathrm{x}$ & $\mathrm{x}$ & $\mathrm{x}$ & & & & $\mathrm{x}$ & $\mathrm{x}$ & & IMS PharMetrics & USA \\
\hline Wu et al. [34], 2008 & $\mathrm{x}$ & $\mathrm{x}$ & $\mathrm{x}$ & & & & $\mathrm{x}$ & & $\mathrm{x}$ & Ingenix employer database & USA \\
\hline Borah et al. [2], 2009 & & $\mathrm{x}$ & $\mathrm{x}$ & & & & $\mathrm{x}$ & $\mathrm{x}$ & & A large health plan & USA \\
\hline Nair et al. [43], 2009 & $\mathrm{x}$ & & & & & & & & $\mathrm{x}$ & MarketScan & USA \\
\hline Ollendorf et al. [33], 2009 & $\mathrm{x}$ & $\mathrm{x}$ & $\mathrm{x}$ & & & & & & $\mathrm{x}$ & IMS PharMetrics & USA \\
\hline Yazici et al. [15], 2009 & $\mathrm{x}$ & $\mathrm{x}$ & $\mathrm{x}$ & & & $\mathrm{x}$ & $\mathrm{x}$ & & $\mathrm{x}$ & IMS PharMetrics & USA \\
\hline Gu et al. [48], 2010 & $\mathrm{x}$ & $\mathrm{x}$ & $\mathrm{x}$ & & & & & & $\mathrm{x}$ & MarketScan & USA \\
\hline Harrison et al. [3], 2010 & $\mathrm{x}$ & $\mathrm{x}$ & $\mathrm{x}$ & & & & $\mathrm{x}$ & & $\mathrm{x}$ & IMS PharMetrics & USA \\
\hline Huang et al. [41], 2010 & & $\mathrm{x}$ & $\mathrm{x}$ & & & & & & $\mathrm{x}$ & MarketScan & USA \\
\hline Li et al. [13], 2010 & $\mathrm{x}$ & & $\mathrm{x}$ & & & $\mathrm{x}$ & $\mathrm{x}$ & $\mathrm{x}$ & & Medicaid Analytic Extract & USA \\
\hline Ogale et al. [17], 2011 & $\mathrm{x}$ & $\mathrm{x}$ & $\mathrm{x}$ & & & $\mathrm{x}$ & $\mathrm{x}$ & & $\mathrm{x}$ & Optum Insight & USA \\
\hline Bolge et al. [40], 2012 & $\mathrm{x}$ & & & & & & & & $\mathrm{x}$ & $\begin{array}{l}\text { HIRD } \\
\text { IMS LifeLink } \\
\text { PPD } \\
\text { WKPS }\end{array}$ & USA \\
\hline Bonafede et al. [49], 2012 & $\mathrm{x}$ & $\mathrm{x}$ & $\mathrm{x}$ & & & $\mathrm{x}$ & $\mathrm{x}$ & & & MarketScan & USA \\
\hline Cho et al. [8], 2012 & $\mathrm{x}$ & $\mathrm{x}$ & $\mathrm{x}$ & & & $\mathrm{x}$ & $\mathrm{x}$ & & & $\begin{array}{l}\text { Korea National Health } \\
\text { Insurance claims database }\end{array}$ & Korea \\
\hline Nguyen-Khoa et al. [50], 2012 & $\mathrm{x}$ & $\mathrm{x}$ & $\mathrm{x}$ & & & $\mathrm{x}$ & & & & MarketScan & USA \\
\hline Thyagarajan et al. [51], 2012 & $\mathrm{x}$ & $\mathrm{x}$ & $\mathrm{x}$ & & & $\mathrm{x}$ & $\mathrm{x}$ & & & Optum Insight & USA \\
\hline Zeidler et al. [4], 2012 & $\mathrm{x}$ & $\mathrm{x}$ & $\mathrm{x}$ & & & & $\mathrm{x}$ & & $\mathrm{x}$ & Helsana Health Insurance & Switzerland \\
\hline Blume et al. [44], 2013 & & $\mathrm{x}$ & $\mathrm{x}$ & & & & $\mathrm{x}$ & & $\mathrm{x}$ & Medco & USA \\
\hline Chastek et al. [37], 2013 & $\mathrm{x}$ & $\mathrm{x}$ & $\mathrm{x}$ & & & & & & $\mathrm{x}$ & Optum Insight & USA \\
\hline Fisher et al. [39], 2013 & $\mathrm{x}$ & $\mathrm{x}$ & $\mathrm{x}$ & & & $\mathrm{x}$ & $\mathrm{x}$ & & $\mathrm{x}$ & HIRD & USA \\
\hline Johnston et al. [18], 2013 & $\mathrm{x}$ & $\mathrm{x}$ & $\mathrm{x}$ & & & $\mathrm{x}$ & & & & MarketScan & USA \\
\hline Curtis et al. [25], 2014a & $\mathrm{x}$ & $\mathrm{x}$ & $\mathrm{x}$ & $\mathrm{x}$ & & $\mathrm{x}$ & & $\mathrm{x}$ & $\mathrm{x}$ & IMS PharMetrics & USA \\
\hline Curtis et al. [26], 2014b & $\mathrm{x}$ & $\mathrm{x}$ & $\mathrm{x}$ & $\mathrm{x}$ & & $\mathrm{x}$ & & $\mathrm{x}$ & $\mathrm{x}$ & MarcetScan & USA \\
\hline Howe et al. [14], 2014 & $\mathrm{x}$ & $\mathrm{x}$ & $\mathrm{x}$ & $\mathrm{x}$ & $\mathrm{x}$ & $\mathrm{x}$ & $\mathrm{x}$ & & & Humana Health Insurance & USA \\
\hline Joyce et al. [36], 2014 & $\mathrm{x}$ & $\mathrm{x}$ & $\mathrm{x}$ & & & & $\mathrm{x}$ & & $\mathrm{x}$ & IMS LifeLink & USA \\
\hline Meissner et al. [16], 2014 & $\mathrm{x}$ & $\mathrm{x}$ & $\mathrm{x}$ & & & $\mathrm{x}$ & & & & IMS PharMetrics & USA \\
\hline Neubauer et al. [9], 2014 & $\mathrm{x}$ & $\mathrm{x}$ & $\mathrm{x}$ & & & $\mathrm{x}$ & $\mathrm{x}$ & & $\mathrm{x}$ & DAK Health Insurance & Germany \\
\hline Oladapo et al. [27], 2014 & $\mathrm{x}$ & $\mathrm{x}$ & $\mathrm{x}$ & & & $\mathrm{x}$ & & $\mathrm{x}$ & $\mathrm{x}$ & Texas Medicaid & USA \\
\hline Tkacz et al. [22], 2014 & & $\mathrm{x}$ & $\mathrm{x}$ & $\mathrm{x}$ & & & $\mathrm{x}$ & $\mathrm{x}$ & & Optum Insight & USA \\
\hline Wu et al. [24], 2014 & $\mathrm{x}$ & $\mathrm{x}$ & $\mathrm{x}$ & $\mathrm{x}$ & $\mathrm{x}$ & $\mathrm{x}$ & $\mathrm{x}$ & & & Medco & USA \\
\hline Bonafede et al. [23], 2015 & $\mathrm{x}$ & $\mathrm{x}$ & $\mathrm{x}$ & $\mathrm{x}$ & $\mathrm{x}$ & $\mathrm{x}$ & $\mathrm{x}$ & $\mathrm{x}$ & $\mathrm{x}$ & MarketScan & USA \\
\hline
\end{tabular}


Table 1 continued

\begin{tabular}{|c|c|c|c|c|c|c|c|c|c|c|c|}
\hline \multirow[t]{2}{*}{ Author [ref.], year } & \multicolumn{5}{|c|}{ TNF inhibitors } & \multicolumn{4}{|c|}{$\begin{array}{l}\text { Mode of change in } \\
\text { dosing: switching (S), } \\
\text { persistence }(\mathrm{P}) \text {, } \\
\text { adherence }(\mathrm{A}) \text {, change } \\
\text { (C) }\end{array}$} & \multicolumn{2}{|l|}{ Source of claims data } \\
\hline & IFX & ADA & ETN & GLM & $\mathrm{CP}$ & $S$ & $\mathrm{P}$ & A & $\mathrm{C}$ & Provider & Country \\
\hline Curtis et al. [28], 2015 & $\mathrm{x}$ & $\mathrm{x}$ & $\mathrm{x}$ & $\mathrm{x}$ & $\mathrm{x}$ & $\mathrm{x}$ & & $\mathrm{x}$ & $\mathrm{x}$ & Optum Research & USA \\
\hline Johnston et al. [20], 2015 & $\mathrm{x}$ & & & & & & $\mathrm{x}$ & & & MarketScan & USA \\
\hline Sangiorgi et al. [10], 2015 & $\mathrm{x}$ & $\mathrm{x}$ & $\mathrm{x}$ & $\mathrm{x}$ & & & $\mathrm{x}$ & & $\mathrm{x}$ & Health-Assisted Subjects Database & Italy \\
\hline Tkacz et al. [31], 2015 & $\mathrm{x}$ & & & & & & $\mathrm{x}$ & $\mathrm{x}$ & & Optum Insight & USA \\
\hline Zhang et al. [29], 2015 & $\mathrm{x}$ & $\mathrm{x}$ & $\mathrm{x}$ & & & & $\mathrm{x}$ & $\mathrm{x}$ & & Medicare & USA \\
\hline Harnett et al. [19], 2016 & $\mathrm{x}$ & $\mathrm{x}$ & $\mathrm{x}$ & $\mathrm{x}$ & $\mathrm{x}$ & $\mathrm{x}$ & $\mathrm{x}$ & & & MarketScan & USA \\
\hline Total & 40 & 34 & 39 & 9 & 5 & 20 & 26 & 14 & 27 & & \\
\hline
\end{tabular}

$A D A$ adalimumab, $C P$ certolizumab pegol, $E T N$ etanercept, $G L M$ golimumab, HIRD HealthCore Integrated Research Database, $I F X$ infliximab, $P P D$ Premier Perspective Database, TNF tumor necrosis factor, WKPS Wolters Kluwer Pharma Solutions, $x$ applied in analysis

Table 2 Definitions of switching

\begin{tabular}{|c|c|c|}
\hline \multirow[t]{2}{*}{ Time frame } & \multicolumn{2}{|c|}{ Discontinuation ensured? } \\
\hline & Yes & Not specified \\
\hline Not specified & Cho et al. [8] & $\begin{array}{l}\text { Bonafede et al. [49] } \\
\text { Nguyen-Khoa et al. [50] } \\
\text { Thyagarajan et al. [51] } \\
\text { Fisher et al. [39] } \\
\text { Curtis et al. [25] } \\
\text { Curtis et al. [26] } \\
\text { Neubauer et al. [9] } \\
\text { Oladapo et al. [27] } \\
\text { Wu et al. [24] } \\
\text { Bonafede et al. [23] } \\
\text { Curtis et al. [28] }\end{array}$ \\
\hline No time frame & Harnett et al. [19] & $\begin{array}{l}\text { Ogale et al. [17] } \\
\text { Johnston et al. [18] } \\
\text { Johnston et al. [20] }\end{array}$ \\
\hline 30 days + DOS & & Yazici et al. [15] \\
\hline 45 days & Howe et al. [14] & \\
\hline 90 days + DOS & $\begin{array}{l}\text { Grijalva et al. [12] } \\
\text { Li et al. [13] }\end{array}$ & \\
\hline $200 \% \times \operatorname{DOS}^{\text {index }}$ & & Meissner et al. [16] \\
\hline
\end{tabular}

DOS days of supply, DOS ${ }^{\text {index }}$ DOS of index prescription

follow-ups, the end of the follow-up can be exceeded by $\operatorname{DOS}_{\mathrm{L}}$, which is the DOS of the last prescription. That happens when the study period ends before the DOS of the last prescription are used. Therefore, Borah et al. truncated the exceeding DOS to avoid overestimating adherence [2]. In the case of variable follow-ups, the follow-up either ends with the last prescription plus $\operatorname{DOS}_{\mathrm{L}}$, when all DOS are used, or at the date of the last prescription. The former was usually performed, whereas the latter was used by Grijalva et al., who excluded the exceeding $\operatorname{DOS}_{\mathrm{L}}$ from the MPR calculation according to [12]:

$\mathrm{MPR}=\frac{\sum_{t=0}^{T} \mathrm{DOS}-\mathrm{DOS}_{\mathrm{L}}}{T}$,

where $T$ indicates the whole study period.

All MPRs can get larger than 1 if more prescriptions are filled than are needed. In such cases, Tkacz et al. normalized the MPR to 1 [22]. This is not necessary with the PDC because it avoids double counting the days where daily doses are on hand [13]. In five studies, PDCs are reported $[13,22,23,28,29]$. Thereof, two studies lacked a precise definition of the PDC calculation. Thus, their methods are not described here [22, 29]. Li et al. [13] gave a very precise description of the PDC. Their method is shown in Figs. 2 and 3. In the case of the subcutaneous (s.c.) application of TNF inhibitors by the patient, the provided syringes are storable (Fig. 2). Therefore, DOS of prescription $V_{1}$ exceeding the date of the next prescription $V_{2}$ can be added to the DOS of prescription $V_{2}$. In contrast, IFX is administered in a clinical setting. Therefore, DOS exceeding the next prescription are not storable (Fig. 3) and premature administration of i.v. drugs does not extend the next expected prescription interval. That is why Li et al. [13] used different procedures for calculating the days with drugs on hand for s.c. and i.v. TNF inhibitors, respectively. Because of the storability of s.c. drugs, the remaining DOS from a previous prescription are added to the following DOS, plus the day of the new prescription, for which adherence can be assumed (Fig. 2). DOS of i.v. and s.c. drugs exceeding the end of the study are excluded. The remaining gap equals the days without medication on hand 
Table 3 Criteria used to describe persistence of medication

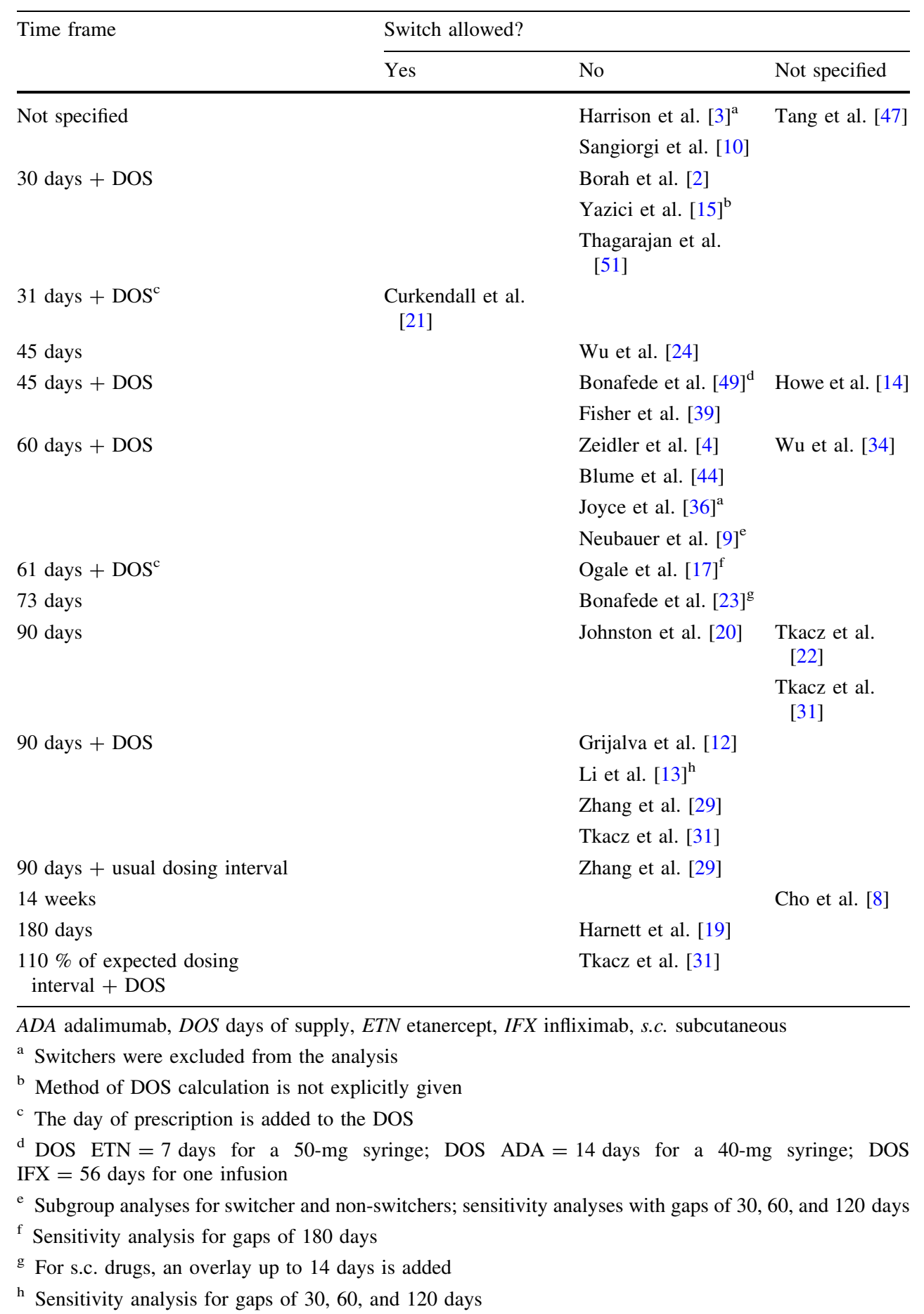

[7]. Curtis et al. and Bonafede et al. used a similar technique, where they limited the added period in s.c. TNF treatment to a maximum of 14 days [23, 28]. Finally, they calculated the PDC for s.c. and i.v. drugs by dividing the days with medication on hand by the time of follow-up [13].

Another measure of adherence is the compliance ratio, used by Harley et al., as well as by Tkacz et al., for injections and infusions alike. It is the ratio between the number of actual and expected prescriptions within a period [30, 31]. It can be larger than 1 if more prescriptions are filled than what was expected.

Although the reported measures of adherence are continuous, it is frequently reported as a binary variable [2, 13, 22, 23, 28-30]. To this end, a threshold for ratios, for example of $80 \%$, is specified, beyond which a patient is considered to be adherent [2, 13, 23, 25, 28-30]. In one study, adherence is not defined as a continuous measure, 


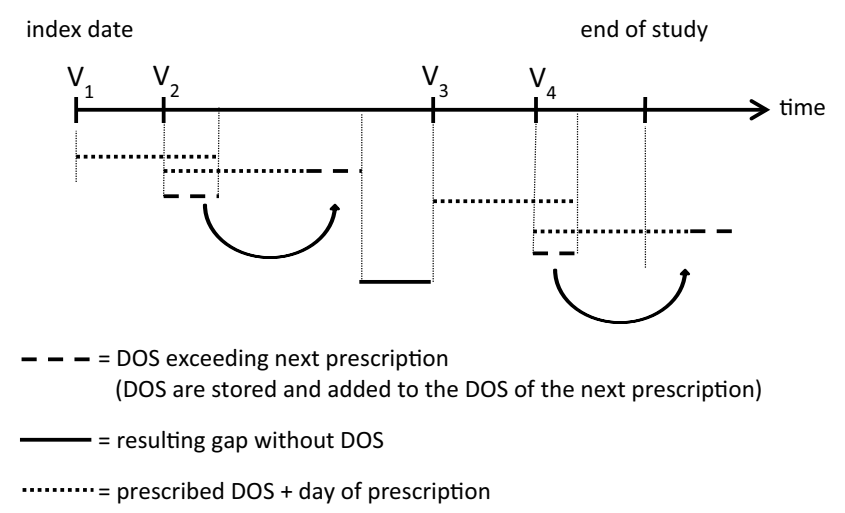

Fig. 2 Proportion of days covered according to Li et al. [13] for subcutaneous drugs. DOS days of supply

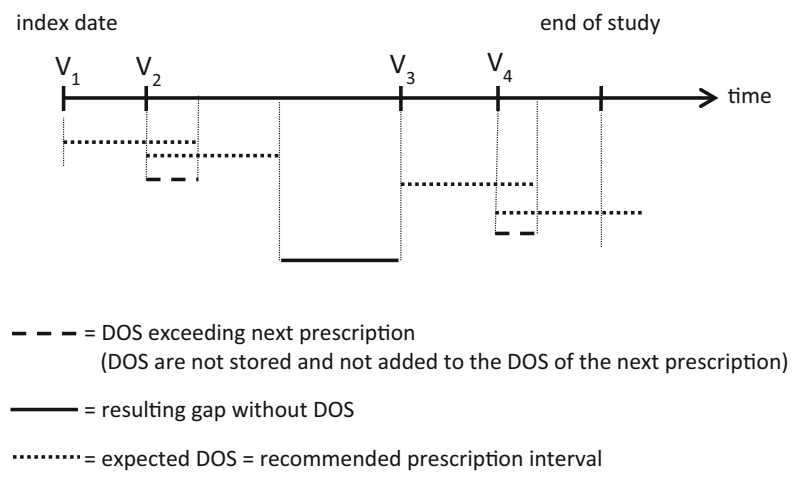

Fig. 3 Proportion of days covered according to Li et al. [13] for intravenous drugs. DOS days of supply

although the MPR and the PDC are reported. Instead, the authors defined a new prescription as adherent if it is filled within 21-38 days after the previous one [22]. Similarly, Curtis et al. defined i.v. therapy as adherent if the number of infusions at least equals the expectations [25-28].

Tkacz et al. also used other novel measures of adherence for infusions based on infusion gaps above expectations and on the number of infusions because DOS were not available for these agents [31]. They accumulated treatment gaps, which are defined as the difference between observed and expected infusion intervals. These gaps were categorized as those that are at least $20 \%$ above expectation on those that do not increase expectation by any amount. They also identified variations in adherence by observing the occurrence of different predefined categories of gaps within a treatment period. Another measure of adherence was defined as the number of infusions in 1 year with gaps of at least $10 \%$ above the expected interval [31].

\subsection{Changes in Dosage}

Changes of prescribed doses can lead to decreases or increases in daily dose. Sometimes, changes exceeding or falling below a certain threshold are required to define an increased or decreased dose. A dosage complying with a definition like that is also called dose escalation. In all studies considering dosage changes, dose escalations were examined. In all, six studies [11, 15, 30, 32-34] considered reductions and four $[11,15,33,34]$ investigated stable doses. One study, where reduced doses are calculated, is not included here because it was missing an explanation and definition of the term 'reduced dose' [29].

A dose has to be compared with a reference dose to decide whether the dose is changed. As a reference, the index dose, the recommended dose, or the previous prescribed dose was used. In the identified literature, usually the first dose after a recommended loading period or the first stable dose was defined as the maintenance dose $[9,10,17,35-40]$.

The dose that is compared with the reference dose usually is the mean daily or mean weekly dose. It is calculated by dividing the absolute prescription dose either by the DOS prescribed or by the prescription interval (see, for example [23, 39, 41, 42] and [10, 11]). In all other studies, the absolute prescription dose was used instead. All but one study used supplementary definitions for changed doses [40]. These definitions are based on the prescription interval or the number of prescriptions within an interval.

\subsubsection{Last Prescription}

The deviation between the last dose and its reference is used for i.v. and s.c. drugs. The variations within this category and the associated studies are shown in Table 4. As references, the index and the maintenance dose were used. The maintenance dose is employed for IFX-naïve patients because of the recommended loading period. However, with s.c. drugs without a loading period or with experienced IFX patients, the index dose was used $[3,36]$. Nevertheless, three studies used the index dose for IFXnaïve patients as well $[11,30,43]$. In most cases, any change in the last dose compared with its reference was sufficient to define a changed dose. Harrison et al. as well as Blume et al. required an increase over $10 \%$ for dose escalation [35, 44]. For IFX and GLM, an increase of the last dose compared with the index dose of at least $100 \mathrm{mg} /$ application and $25 \mathrm{mg} /$ week were required in four [25-28] and three studies, respectively [25, 26, 28].

\subsubsection{Any Prescription}

The definitions used for any dose compared with its reference over the follow-up are shown in Table 5. In such a way, the index, maintenance, recommended, or previous doses were used. These reference doses were applied to s.c. 
Table 4 Criteria used for the definition of 'last prescription'

\begin{tabular}{lll}
\hline Change in dose & Reference dose & \\
\cline { 2 - 3 } & Index dose & Maintenance dose \\
\hline Any & Harley et al. [30] & Joyce et al. [36] \\
& Berger et al. [32] & \\
& Weycker et al. [11] & \\
& Nair et al. [43] & \\
& Harrison et al. [3] \\
& Huang et al. [41] \\
& Joyce et al. [36] \\
& Harrison et al. [3] & Harrison et al. [3] \\
& Blume et al. [44] & \\
$10 \%$ & Curtis et al. [25] \\
& Curtis et al. [26] \\
& Oladapo et al. [27] & \\
& Curtis et al. [28] & \\
& Curtis et al. [25] \\
& Curtis et al. [26] \\
& Curtis et al. [28] \\
\hline
\end{tabular}

GLM golimumab, IFX infliximab

${ }^{a}$ In the case of IFX, the change in dose refers to the absolute prescribed dose, not to the mean daily dose between two prescriptions. To consider time, a reduction in the length of a prescription interval or an increased number of infusions is also defined as an increased dose according to Table 7

injections and infusions alike. In 19 records, any increase or decrease of a prescription was defined as a dosage change. In other studies, various minimum thresholds were defined. These thresholds ranged from 10 to $100 \%$. Furthermore, some methods require these changes in at least two consecutive observations [10, 17, 33, 44, 37].

In four studies, no reference for dosage analyses of ADA and ETN was used [25-28]. These studies are shown in Table 6. Here, a weekly prescription dose of at least $40 \mathrm{mg}$ ADA or $100 \mathrm{mg}$ ETN was sufficient for dose escalation.

As opposed to s.c. agents, daily doses are difficult to calculate with IFX, because for infusions, DOS are not given in the claims data and appropriate IFX dosage is dependent on the patient's weight [16, 45]. Therefore, a supplementary definition of dose increase with IFX is often defined with reduced prescription intervals [35, 34, 39, 46] or an increased number of infusions within a certain period $[17,25-28,38]$ as depicted in Table 7 . Sometimes, this increase must be observed in at least two occasions [17, 38, 46]. For example, Curtis et al. considered a prescription quantity of more than $120 \%$ of that which was expected as an increase in dose [25-28]. In other cases, reductions in the recommended infusions period of 8 weeks [45] to either fewer than 6 or fewer than 7 weeks was defined as an increase in dose [34, 46, 39].
Wu et al. are the only individuals who defined reduced doses within this class of methods [34]. They also applied a particularly complex method to patients who did not start with the recommended dose [34]. The authors defined a change in dosage in ADA and ETN therapies from the healthcare provider's point of view. They assigned the mean doses of the treatment of naïve patients into four dosage categories. Mean doses were calculated differently according to the prescription gaps. If gaps were small or negative, the DOS given in the prescriptions were taken as the denominator. Otherwise, the prescription interval was used. Accordingly, the prescribed mean dose was used in the former case, whereas the real mean dose seemed more appropriate to the authors in the last case. The resulting dosage categories were applied to define a change in dose using the first stable dose as a reference. An increase or decrease in dose was defined as at least two switches to a higher or lower class, respectively. The first stable dose was defined as the second prescribed dose if the first and second doses were the same. If the second and third doses were equal, the third dose was defined as the first stable dose. Otherwise, the mean value of the first three prescribed doses was used. If fewer than three prescriptions were available, the index dose was used as the reference.

\subsubsection{All Prescriptions}

With this approach of calculating mean doses, all prescriptions within a certain period are taken into account (Table 8). The recommended, the index, or the maintenance dose is compared with the mean dose of all prescriptions of a specific period. If the index or maintenance dose is the reference, it was excluded from the calculation. Two exceptions are the studies of Zeidler et al. and Fisher et al. where the maintenance dose was included [4, 39]. Huang et al. determined the mean dose for each period between the index dose and every following prescription [41]. To identify a dose escalation, at least two of these mean values had to be greater than the index dose [41]. As in the previous methods, a certain threshold was defined in some studies to determine a changed dose.

\section{Discussion}

The objective of the present systematic review was to describe and assess methods in published dosage analyses of TNF inhibitor therapy of patients with RA based on claims data. The methods of the identified 45 studies of relevance were compared and grouped into switching, adherence, persistence, and dosage-change analyses.

In switching analyses, a certain time frame where switching must occur was rarely used (Table 2). It should 
Table 5 Criteria used for the definition of 'any prescription'

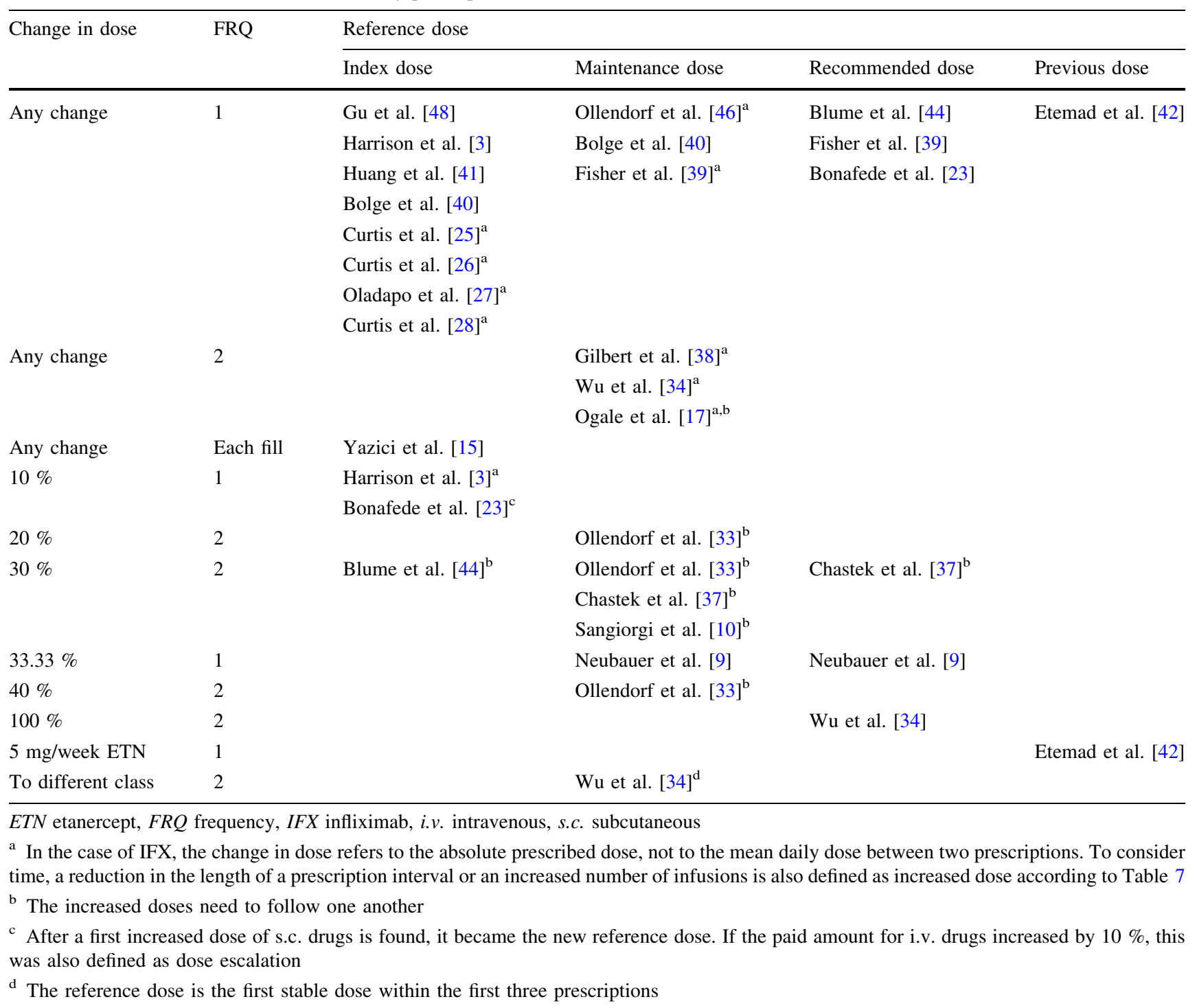

Table 6 Criteria used for the definition of 'any prescription'

\begin{tabular}{lll}
\hline Change in absolute prescription dose & FRQ & No reference dose \\
\hline$\geq 40 \mathrm{mg} /$ week (ADA) & 1 & Curtis et al. [25] \\
& & Curtis et al. [26] \\
& & Oladapo et al. [27] \\
& & Curtis et al. [28] \\
$\geq 100 \mathrm{mg} /$ week (ETN) & 1 & Curtis et al. [25] \\
& & Curtis et al. [26] \\
& & Oladapo et al. [27] \\
& & Curtis et al. [28]
\end{tabular}

$A D A$ adalimumab, ETN etanercept, $F R Q$ frequency

be noted that if a time frame is not used, persistency within treatment cannot be ensured. Furthermore, if the termination of the previous treatment is not verified, it is not possible to differentiate co-medication from switching.
For persistence analyses, the usefulness of a time frame should be also considered. With very small gaps, patients who are not $100 \%$ adherent will be considered non-persistent. Given the widely accepted adherence level of $80 \%$, this assumption seems not to be plausible. However, very large gaps could overestimate persistence, if persistency is mixed with termination and restart of therapy. To our knowledge, there is no widely accepted standard for the length of the time gap in persistence analyses. Therefore, sensitivity analyses with varying prescription gaps may be useful.

When the MPR is used, analysts should bear in mind that the MPR in contrast to the PDC is a simple summation of DOS divided by the treatment period (Sect. 3.2.3). The PDC is slightly more complicated to calculate but its assumptions concerning the storability of different drugs seem to be more realistic (Figs. 2, 3). With the PDC, days 
Table 7 Supplementary definition of dose escalation in case of IFX dosage analyses

\begin{tabular}{|c|c|c|}
\hline Change in prescription interval or number of infusions & FRQ & Article \\
\hline \multicolumn{3}{|l|}{ Changed prescription interval } \\
\hline Any change from index to last prescription interval & 1 & Harrison et al. [3] \\
\hline Prescription interval of $<6$ weeks & 1 & Fisher et al. [39] \\
\hline \multirow[t]{2}{*}{ Prescription interval of $<7$ weeks } & 1 & Wu et al. [34] \\
\hline & 2 & Ollendorf et al. [46] \\
\hline Prescription interval of $>9$ weeks (definition of decreased dose) & 1 & Wu et al. [34] \\
\hline \multicolumn{3}{|l|}{ Changed number of infusions } \\
\hline \multirow[t]{4}{*}{ Increased number of infusions of $>20 \%$ compared with expectation } & 1 & Curtis et al. [25] \\
\hline & & Curtis et al. [26] \\
\hline & & Oladapo et al. [27] \\
\hline & & Curtis et al. [28] \\
\hline \multirow[t]{2}{*}{$\geq 2$ infusions within 7 weeks } & 2 & Gilbert et al. [38] \\
\hline & & Ogale et al. [17] \\
\hline
\end{tabular}

$F R Q$ frequency, $I F X$ infliximab

Table 8 Criteria used for the definition of 'all prescriptions'

\begin{tabular}{|c|c|c|c|c|}
\hline \multirow[t]{2}{*}{ Change } & \multirow[t]{2}{*}{ Dose of interest: mean dose calculated for the period } & \multicolumn{3}{|l|}{ Reference dose } \\
\hline & & Index dose & Maintenance dose & Recommended dose \\
\hline \multirow[t]{5}{*}{ Any change } & After reference dose to each subsequent prescription & Huang et al. $[41]^{\mathrm{a}}$ & & \\
\hline & & Joyce et al. [36] & & \\
\hline & After reference dose to end of follow-up & & Joyce et al. [36] & \\
\hline & Of the entire follow-up & & & Huang et al. [41] \\
\hline & & & & Joyce et al., 2014 [36] \\
\hline \multirow[t]{2}{*}{$10 \%$} & Of the entire follow-up & & Fisher et al., 2013 [39] & Blume et al. [44] \\
\hline & & & & Fisher et al. [39] \\
\hline $15 \%$ & After reference dose to end of follow-up & Huang et al. [41] & & \\
\hline \multirow[t]{2}{*}{$30 \%$} & After reference dose to end of follow-up & Huang et al. [41] & Chastek et al. [37] & \\
\hline & & Blume et al. [44] & & \\
\hline \multirow[t]{3}{*}{$33.3 \%$} & After reference dose to end of follow-up & & Wu et al. [34] & \\
\hline & Of the entire follow-up & & Zeidler et al. [4] & Wu et al. [34] \\
\hline & & & & Zeidler et al. [4] \\
\hline $50 \%$ & After reference dose to end of follow-up & Huang et al. [41] & & \\
\hline
\end{tabular}

${ }^{a}$ In comparison to the index dose, the mean weekly dose must be increased at least two times

with drugs on hand that exceed the next prescription are just carried over into the future and not into the gaps in the past. In contrast to the calculation of the MPR, all DOS within the follow-up period are taken into account. Therefore, DOS exceeding the next prescription can offset prescription gaps in the past as well as in the future. Hence, the MPR may overestimate persistence, as compared with PDC.

There is a wide variety of dosage change analyses. The calculation of 'last prescription vs. reference' may be one of the easiest, but it does not consider interim changes in doses. In contrast, 'any dose vs. reference' takes every prescription into account. Therefore, it is a very sensitive method and could overestimate changes in dose, for example, when the increased prescription is an outlier or error in the claims data. Therefore, sensitivity analyses with different methods and varying thresholds could be conducted or, for definition of dose decrease or escalation, multiple dosage changes could be required [10, 34, 33, 38]. Because with 'every dose vs. reference' the overall prescription mean is compared, the influence of an outlier could be diminished. However, it should be noted that with exception of the method of $\mathrm{Wu}$ et al., where a new prescription mean after each prescription is calculated, the 
course of the dosage over the treatment period cannot be identified [34].

As reference doses, observable prescription doses within therapy such as the index dose, maintenance dose, or the previous dose may be advisable if changes within therapy should be identified. If treatments should be compared with treatment recommendations, for example, for guideline evaluations, a suitable reference dose may be the recommended dose. The interpretation of the index dose depends on the definition on the patient's experience. If the study analyzes treatment-naïve patients, the index dose equals the initial dose, which is the first treatment dose. Otherwise, if experienced patients are analyzed or if no loading period is recommended, the index dose and maintenance dose could be the same. The loading period is the first period of the therapy where the maintenance level has not been reached.

Because of the high impact of dosage on costs and the impact of the virtue of therapy on adherence, persistence, and dose, dosage analyses are important for healthcare payers, healthcare providers, and patients alike. To facilitate further claims data-based research in this area, we present a comprehensive overview and a short discussion of current methods. Because we did not assess quality of methods quantitatively, further research in this area is needed.

The present study is limited to publications in the English or German languages. Furthermore, a detailed explanation of the methods used was not provided in every study. Hence, opportunities for comparison are restricted. Moreover, most studies are performed with US claims data. Owing to restrictions in available data, the methods reviewed in this study may not generalize to every country.

\section{Conclusions}

This systematic review identified a high variation of methods used in dosage analyses applied to claims data of TNF inhibitor treatment among patients with RA. Our information and suggestions may be helpful for choosing appropriate methods in future studies and greatly facilitate further dosage analyses. Additionally, the presented systematic comparison of methods demonstrates the need for standardized methodology concerning the design, conduct, analysis, and reporting of claims data studies in rheumatology. Evidence-based methodology is a prerequisite for cross-study comparisons and to reliably calculate the healthcare costs of TNF inhibitors in actual patients with RA.

Acknowledgments The authors thank Prof. Dr. Reiner Leidl for his review and helpful suggestions.

\section{Compliance with Ethical Standards}

Funding No financial support or benefits have been or will be received.

Conflict of interest Gundula Krack, Henning Zeidler and Jan Zeidler confirm that they have no financial interests that would create a potential conflict of interest with regard to the work.

Open Access This article is distributed under the terms of the Creative Commons Attribution-NonCommercial 4.0 International License (http://creativecommons.org/licenses/by-nc/4.0/), which permits any noncommercial use, distribution, and reproduction in any medium, provided you give appropriate credit to the original author(s) and the source, provide a link to the Creative Commons license, and indicate if changes were made.

\section{References}

1. Feldmann M. Development of anti-TNF therapy for rheumatoid arthritis. Nat Rev Immunol. 2002;2:364-71.

2. Borah BJ, Huang X, Zarotsky V, Globe D. Trends in RA patients' adherence to subcutaneous anti-TNF therapies and costs. Curr Med Res Opin. 2009;25:1365-77. doi:10.1185/ 03007990902896386.

3. Harrison DJ, Huang X, Globe D. Dosing patterns and costs of tumor necrosis factor inhibitor use for rheumatoid arthritis. Am J Health Syst Pharm. 2010;67:1281-7. doi:10.2146/ajhp090487.

4. Zeidler J, Mittendorf T, Muller R, von Kempis J. Biologic TNF inhibiting agents for treatment of inflammatory rheumatic diseases: dosing patterns and related costs in Switzerland from a payers perspective. Health Econ Rev. 2012;2:20. doi:10.1186/ 2191-1991-2-20.

5. Zeidler J, Braun S. 2 Sekundärdatenanalysen. In: Schöffski O, Graf von der Schulenburg JM, editors. Gesundheitsökonomische evaluationen. Berlin: Springer; 2012. p. 243-74.

6. DIMDI. Database search. http://www.dimdi.de/static/en/db/ index.htm. Accessed 29 Sept 2015.

7. Cramer JA, Roy A, Burrell A, et al. Medication compliance and persistence: terminology and definitions. Value Health. 2008;11:44-7. doi:10.1111/j.1524-4733.2007.00213.x.

8. Cho SK, Sung YK, Choi CB, Bae SC. Impact of comorbidities on TNF inhibitor persistence in rheumatoid arthritis patients: an analysis of Korean National Health Insurance claims data. Rheumatol Int. 2012;32:3851-6. doi:10.1007/s00296-011-23121.

9. Neubauer S, Cifaldi M, Mittendorf T, et al. Biologic TNF inhibiting agents for treatment of rheumatoid arthritis: persistence and dosing patterns in Germany. Health Econ Rev. 2014;4:1-11.

10. Sangiorgi D, Benucci M, Nappi C, et al. Drug usage analysis and health care resources consumption in naïve patients with rheumatoid arthritis. Biologics. 2015;9:119-27.

11. Weycker D, Yu EB, Woolley JM, Oster G. Retrospective study of the costs of care during the first year of therapy with etanercept or infliximab among patients aged $\geq 65$ years with rheumatoid arthritis. Clin Ther. 2005;27:646-56.

12. Grijalva CG, Chung CP, Arbogast PG, et al. Assessment of adherence to and persistence on disease-modifying antirheumatic drugs (DMARDs) in patients with rheumatoid arthritis. Med Care. 2007;45:S66-76. doi:10.1097/MLR.0b013e318041384c.

13. Li P, Blum MA, Von Feldt J, et al. Adherence, discontinuation, and switching of biologic therapies in Medicaid enrollees with rheumatoid arthritis. Value Health. 2010;13:805-12. doi:10.1111/ j.1524-4733.2010.00764.x. 
14. Howe A, Eyck LT, Dufour R, et al. Treatment patterns and annual drug costs of biologic therapies across indications from the Humana commercial database. J Manag Care Pharm. 2014;20(12):1236-44.

15. Yazici Y, Krasnokutsky S, Barnes JP, et al. Changing patterns of tumor necrosis factor inhibitor use in 9074 patients with rheumatoid arthritis. J Rheumatol. 2009;36:907-13. doi:10.3899/ jrheum.080592.

16. Meissner B, Trivedi D, You M, Rosenblatt L. Switching of biologic disease modifying anti-rheumatic drugs in patients with rheumatoid arthritis in a real world setting. J Med Econ. 2014;17:259-65. doi:10.3111/13696998.2014.893241.

17. Ogale S, Hitraya E, Henk HJ. Patterns of biologic agent utilization among patients with rheumatoid arthritis: a retrospective cohort study. BMC Musculoskelet Disord. 2011;12:204. doi:10. 1186/1471-2474-12-204.

18. Johnston SS, Turpcu A, Shi N, et al. Risk of infections in rheumatoid arthritis patients switching from anti-TNF agents to rituximab, abatacept, or another anti-TNF agent, a retrospective administrative claims analysis. Semin Arthritis Rheum. 2013;43:39-47. doi:10.1016/j.semarthrit.2012.12.024.

19. Harnett J, Wiederkehr D, Gerber R, et al. Real-world evaluation of TNF-inhibitor utilization in rheumatoid arthritis. J Med Econ. 2016;19:91-102.

20. Johnston SS, McMorrow D, Farr AM, et al. Comparison of healthcare costs between rheumatoid arthritis patients treated with infused biologics after switching from another biologic. Drugs Real World Outcomes. 2015;2:99-109.

21. Curkendall S, Patel V, Gleeson M, et al. Compliance with biologic therapies for rheumatoid arthritis: do patient out-of-pocket payments matter? Arthritis Rheum. 2008;59:1519-26. doi:10. 1002/art.24114.

22. Tkacz J, Ellis L, Bolge SC, et al. Utilization and adherence patterns of subcutaneously administered anti-tumor necrosis factor treatment among rheumatoid arthritis patients. Clin Ther. 2014;36:737-47. doi:10.1016/j.clinthera.2014.02.019.

23. Bonafede M, Johnson BH, Princic N, et al. Cost per patient-year in response using a claims-based algorithm for the 2 years following biologic initiation in patients with rheumatoid arthritis. J Med Econ. 2015;18:376-89.

24. Wu N, Shah N, Harrison DJ. Cost of biologics per treated patient across immune-mediated inflammatory disease indications in a pharmacy benefit management setting: a retrospective cohort study. Clin Ther. 2014;36(8):1231-41. e3.

25. Curtis JR, Schabert VF, Yeaw J, et al. Use of a validated algorithm to estimate the annual cost of effective biologic treatment for rheumatoid arthritis. J Med Econ. 2014;17:555-66. doi:10. 3111/13696998.2014.914031.

26. Curtis JR, Schabert VF, Harrison DJ, et al. Estimating effectiveness and cost of biologics for rheumatoid arthritis: application of a validated algorithm to commercial insurance claims. Clin Ther. 2014;36:996-1004.

27. Oladapo A, Barner JC, Lawson KA, et al. Medication effectiveness with the use of tumor necrosis factor inhibitors among Texas Medicaid patients diagnosed with rheumatoid arthritis. J Manag Care Pharm. 2014;20:657-67.

28. Curtis JR, Chastek B, Becker L, et al. Cost and effectiveness of biologics for rheumatoid arthritis in a commercially insured population. J Manag Care Spec Pharm. 2015;21:318-29.

29. Zhang J, Xie F, Delzell E, et al. Impact of biologic agents with and without concomitant methotrexate and at reduced doses in older rheumatoid arthritis patients. Arthritis Care Res. 2015;67:624-32.

30. Harley CR, Frytak JR, Tandon N. Treatment compliance and dosage administration among rheumatoid arthritis patients receiving infliximab, etanercept, or methotrexate. Am J Manag Care. 2003;9:S136-43.

31. Tkacz J, Ingham MP, Brady BL, et al. Novel adherence measures for infusible therapeutic agents indicated for rheumatoid arthritis. Am Health Drug Benefits. 2015;8(9):494.

32. Berger A, Edelsberg J, Li TT, et al. Dose intensification with infliximab in patients with rheumatoid arthritis. Ann Pharmacother. 2005;39:2021-5. doi:10.1345/aph.1G264.

33. Ollendorf DA, Klingman D, Hazard E, Ray S. Differences in annual medication costs and rates of dosage increase between tumor necrosis factor-antagonist therapies for rheumatoid arthritis in a managed care population. Clin Ther. 2009;31:825-35. doi:10.1016/j.clinthera.2009.04.002.

34. Wu E, Chen L, Birnbaum H, et al. Retrospective claims data analysis of dosage adjustment patterns of TNF antagonists among patients with rheumatoid arthritis. Curr Med Res Opin. 2008;24:2229-40. doi:10.1185/03007990802229548.

35. Harrison DJ, Huang X, Globe D. Dosing patterns and costs of tumor necrosis factor inhibitor use for rheumatoid arthritis. Am J Health Syst Pharm. 2010;67(15):1281-7. doi:10.2146/ajhp090487.

36. Joyce AT, Gandra SR, Fox KM, et al. National and regional dose escalation and cost of tumor necrosis factor blocker therapy in biologic-naive rheumatoid arthritis patients in US health plans. J Med Econ. 2014;17(1):1-10. doi:10.3111/13696998.2013. 856314.

37. Chastek B, Segal SD, Bonafede P, et al. Comparative effectiveness of TNF blockers in rheumatoid arthritis patients. Am J Pharm Benefits. 2013;5(Special Issue):SP14-22.

38. Gilbert TD Jr, Smith D, Ollendorf DA. Patterns of use, dosing, and economic impact of biologic agent use in patients with rheumatoid arthritis: a retrospective cohort study. BMC Musculoskelet Disord. 2004;5:36. doi:10.1186/1471-2474-5-36.

39. Fisher MD, Watson C, Fox KM, et al. Dosing patterns of three tumor necrosis factor blockers among patients with rheumatoid arthritis in a large United States managed care population. Curr Med Res Opin. 2013;29(5):561-8. doi:10.1185/03007995.2013. 786693.

40. Bolge SC, Carter CT, Mueller CS, et al. Comparative multidatabase analysis of dosing patterns and infusion intervals for the first 12 infliximab infusions in patients with rheumatoid arthritis. Clin Ther. 2012;34(12):2286-92. doi:10.1016/j.clinthera.2012. 10.010 .

41. Huang X, Gu NY, Fox KM, et al. Comparison of methods for measuring dose escalation of the subcutaneous TNF antagonists for rheumatoid arthritis patients treated in routine clinical practice. Curr Med Res Opin. 2010;26(7):1637-45. doi:10.1185/ 03007995.2010.483127.

42. Etemad L, Yu EB, Wanke LA. Dose adjustment over time of etanercept and infliximab in patients with rheumatoid arthritis. Manag Care Interface. 2005;18(4):21-7.

43. Nair KV, Tang B, Van Den Bos J, et al. Categorization of infliximab dose changes and healthcare utilization and expenditures for patients with rheumatoid arthritis in commercially insured and Medicare-eligible populations. Curr Med Res Opin. 2009;25:303-14. doi:10.1185/03007990802598736.

44. Blume SW, Fox KM, Joseph G, et al. Tumor necrosis factorblocker dose escalation in rheumatoid arthritis patients in a pharmacy benefit management setting. Adv Ther. 2013;30:517-27. doi:10.1007/s12325-013-0034-3.

45. MSD. Fachinformation Remicade ${ }^{\circledR} 100 \mathrm{mg}$ (summary of product characteristics). 2013.

46. Ollendorf DA, Massarotti E, Birbara C, Burgess SM. Frequency, predictors, and economic impact of upward dose adjustment of infliximab in managed care patients with rheumatoid arthritis. J Manag Care Pharm. 2005;11:383-93. 
47. Tang B, Rahman M, Waters HC, Callegari P. Treatment persistence with adalimumab, etanercept, or infliximab in combination with methotrexate and the effects on health care costs in patients with rheumatoid arthritis. Clin Ther. 2008;30:1375-84.

48. Gu NY, Huang X, Fox KM, et al. Claims data analysis of dosing and cost of TNF antagonists. Am $J$ Pharm Benefits. 2010;2:351-9.

49. Bonafede M, Fox KM, Watson C, et al. Treatment patterns in the first year after initiating tumor necrosis factor blockers in realworld settings. Adv Ther. 2012;29:664-74. doi:10.1007/s12325012-0037-5.
50. Nguyen-Khoa BA, Goehring EL Jr, Alexander KA, et al. Risk of significant infection in rheumatoid arthritis patients switching anti-tumor necrosis factor-alpha drugs. Semin Arthritis Rheum. 2012;42:119-26. doi:10.1016/j.semarthrit.2012.04.001.

51. Thyagarajan V, Norman H, Alexander KA, et al. Risk of mortality, fatal infection, and fatal malignancy related to use of antitumor necrosis factor-alpha biologics by rheumatoid arthritis patients. Semin Arthritis Rheum. 2012;42:223-33. doi:10.1016/j. semarthrit.2012.05.004. 